\title{
$\mathrm{ATSC}$ 지상파 DTV 시스템에서 TxID를 이용한 부가데이터 전송 기법
}

\author{
강 동 훈 ${ }^{a)}$, 박 성 익 ${ }^{b)}$, 김 흥 묵 ${ }^{b)}$, 오 왕 록 ${ }^{a^{\ddagger}}$
}

\section{Additional Data Transmission Scheme Using TxID Signal for ATSC System}

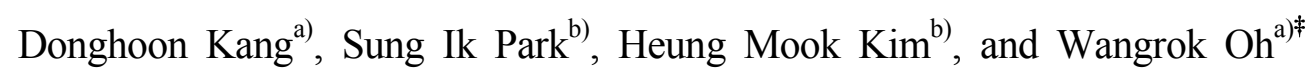 \\ 요 약
}

ATSC (Advanced Television Systems Committee) 지상파 DTV 시스템에서 단일 주파수 망 (Single Frequency Network) 구성 시 동일한 주파수 대역을 사용하는 다수의 송신기와 중계기들로 인하여 수신기에서는 필연적으로 간섭이 발생하게 된다. 이러한 간섭 문제를 해결하기 위하여 ATSC recommended practice (RP) A/111에서는 Kasami 수열로 구성된 송신 식별 (Transmitter Identification, TxID) 신호를 각 송신기 및 중계기에 할당하고 이를 송신 신호에 부가하여 전송한다. 본 논문에서는 TxID 신호로 제 안된 Kasami 수열의 극성 및 위상을 조절하여 부가데이터를 전송하는 기법을 제안한다. 제안하는 기법에서 Kasami 수열은 송신기 및 중계기를 식별하기위한 TxID 신호로서의 기능을 수행할 뿐만 아니라 추가적으로 부가데이터를 전송할 수 있는 장점이 있다.

\section{Abstract}

In a Single Frequency Network (SFN) for Advanced Television Systems Committee (ATSC) terrestrial digital television (DTV) system, the interferences induced by the multiple transmitters and/or repeaters using same frequency are unavoidable. To ease the interference handing in the SFN for ATSC DTV system, transmitter identification (TxID) signal is recommended in the ATSC terrestrial DTV system. The TxID signal is embedded in the ATSC DTV signal and transmitted from each transmitter and repeater within the SFN and in ATSC recommended practice (RP) A/111, Kasami sequence is recommended as the TxID signal. In this paper, we propose an additional data transmission scheme using the TxID signal. In the proposed scheme, the Kasami sequence not only acts as the conventional TxID of the SFN for ATSC terrestrial DTV system but also carriers the additional data bits on its polarity and the code phase.

Keyword: ATSC, TxID, Additional data transmission, Kasami sequence

a) 충남대학교 정보통신공학과

Dept. of Information and Communications Engineering, Chungnam National University

b) 한국전자통신연구원 방송시스템연구부

Broadcasting System Research Department, ETRI

\# 교신저자 : 오왕록 (kingrock@cnu.ac.kr)

※ 본 연구는 지식경제부, 방송통신위원회 및 한국산업기술평가관리원의 산업원천기술개발사업(정보통신)의 일환으로 수행하였음. [KI002067, 지상파 DTV 전송효율고도화기술개발]

· 접수일(2010년10월11일),수정일(2010년12월13일),게재확정일(2010년12 월31일)

\section{Introduction}

일반적으로 지상파 방송 시스템은 송신기 및 중계기 간 동일 채널 간섭 (Co-channel interference)을 방지하기 위하 여 각각의 송신기 및 중계기에 서로 다른 주파수를 할당하 여 방송망을 구성하는 다중 주파수 망 (MFN, Multiple Frequency Network) 방식을 통하여 서비스된다. 이러한 
MFN 방식을 이용하여 시스템을 구성할 경우 각각의 송신 기 및 중계기에 서로 다른 주파수를 할당하여야하므로 주 파수 이용효율이 낮은 단점이 있다. 일반적으로 MFN 방식 의 주파수 이용효율을 높이기 위하여 주파수 재사용 (frequency reuse) 기법을 사용한다. MFN 방식에서 주파수 재 사용 기법을 사용하더라도 동일 채널 간섭으로 인하여 송 신기 및 중계기들 간의 거리가 충분히 먼 곳을 제외하고는 동일한 주파수를 사용할 수 없기 때문에 MFN 방식은 주 파수 이용 관점에서 비효율적인 방송망 구성 방법이다. 따라서 지상파 방송 시스템의 주파수 이용효율을 높이기 위하여 디지털 방송 시스템에서 단일 주파수 망 (SFN, single frequency network)을 이용하여 구성하는 방안이 제 안되었다 ${ }^{[1]}$.

ATSC (Advanced Television Systems Committee) 지상 파 DTV 시스템에서 SFN 구성을 위한 기술로는 송신기 간 에 동일한 주파수를 사용하는 분산 송신기 (DTxT, Distributed Transmitters), 송신기와 중계기가 동일 주파수 를 사용하는 디지털 동일채널 중계기 (DOCR, Digital On-Channel Repeaters), 중계기 간에 동일 주파수를 사용하 는 분산 중계기 (Distributed Translators) 기술로 나누어진 다 ${ }^{[2-4]} \mathrm{SFN}$ 을 이용하여 망을 구성할 경우 주파수 이용효율 은 높일 수 있으나 동일한 주파수를 사용하는 다수의 송신 기 및 중계기로 인하여 동일 채널 간섭 (Co-channel interference)이 발생한다. 이러한 동일 채널 간섭은 송신기 및 중계기로부터 수신된 파워 및 시간 지연을 갖는 페이딩 채 널의 전력 지연 분포를 분석하여 주변 송신기 및 중계기의 송신 파워 및 상대적인 송출시간을 조정함으로서 제거할 수 있다. ATSC Recommended Practice (RP) A/111에서는 $\mathrm{SFN}$ 에서 채널 환경을 추정하기 위한 방안으로 자기 상관 특성이 우수한 Kasami 수열로 구성된 TxID (transmitter identification) 신호를 각 송신기 및 중계기에 할당하고 송 신 및 중계신호에 부가하여 전송한다다. TxID 신호는 TxID 신호 분석기를 이용하여 추출 및 분석이 가능하고, 이를 이 용하여 SFN에서 각 송신기 및 중계기에 의하여 발생되는 채널 환경을 추정할 수 있다 ${ }^{[6]}$.

기존에 TxID 신호를 이용하여 부가적인 신호를 전송하 는 방안이 제안되었다 ${ }^{[7,8]}$. 기존에 제안된 부가데이터 전송
기법에서는 TxID 신호를 구성하는 Kasami 수열의 극성만 을 이용하여 부가데이터를 전송한다. 따라서 부가데이터의 최대 전송율이 $165 \mathrm{bps}$ 로 낮은 전송율을 갖는다. 또한 AWGN (additive white Gaussian noise) 채널을 고려하였을 때 기존에 제안된 부가데이터 전송 기법에서 안정적인 통 신을 위하여 요구되는 최소한의 CNR (carrier-to-noise ratio)은 $1.5 \mathrm{~dB}$ 이다. 기존에 제안된 부가데이터 전송 기법은 Kasami 수열을 이용하여 넓은 주파수 대역으로 신호를 확 산시켜 전송한다. 따라서 $1.5 \mathrm{~dB}$ 보다 낮은 $\mathrm{CNR}$ 영역에서 통신이 가능하지만 기존의 ATSC DTV 시스템에서 주파수 및 시간 동기를 맞추기 위해서 필요한 최소한의 CNR이 1.5 $\mathrm{dB}$ 이므로 실제 부가데이터 전송기법이 동작하기 시작하는 $\mathrm{CNR}$ 은 $1.5 \mathrm{~dB}$ 이다. 기존에 제안된 부가데이터 전송 기법 의 동작 영역은 ATSC DTV 신호가 동작하는 $\mathrm{CNR}$ 보다 $13.5 \mathrm{~dB}$ 낮은 영역에서 동작하므로 ATSC DTV 신호보다 더 넓은 영역의 통신 반경을 갖는다.

본 논문에서는 TxID 신호를 구성하는 Kasami 수열의 위 상 및 극성을 이용하여 부가데이터를 전송하는 기법을 제 안한다. 제안하는 기법에서는 안정적인 통신을 위하여 요 구되는 최소한의 $\mathrm{CNR}$ 값이 기존에 제안된 기법과 동일하면 서도 더 많은 부가데이터를 전송하는 것이 가능하다. 또한 제안하는 기법에서 사용하는 Kasami 수열은 ATSC RP $\mathrm{A} / 111$ 에서 제안하는 송신기 및 중계기 식별 신호로서의 역 할을 수행할 뿐만 아니라 최대 $1.157 \mathrm{kbps}$ 의 데이터를 추가 적으로 전송할 수 있다. 본 논문의 구성은 다음과 같다. 2장 에서는 제안하는 부가데이터 전송 기법의 송-수신기 구조 를 보이고 3장에서 제안하는 부가데이터 전송 기법의 성능 에 대한 전산 실험 결과를 제시한다. 마지막으로 4장에서 본 논문의 결론을 맺는다.

\section{Additional Data Transmission Scheme}

\section{TxID Signal Transmission}

SFN 방식으로 구성된 ATSC 지상파 DTV 시스템에서 송신기 및 중계기는 송신 식별 신호로서 TxID 신호를 
ATSC DTV 신호에 삽입하여 전송한다. ATSC RP A/111 에서는 자기상관 (Auto-correlation) 및 상호상관 (Crosscorrelation) 특성이 우수한 Kasami 수열을 TxID 신호로 사 용한다. 이진 수열인 Kasami 수열은 생성다항식 (generator polynomial)의 차수 $n$ 이 짝수일 경우에만 수열이 존재하며 그때 수열의 길이 $N$ 은 $2^{n}-1$ 의 값을 갖는다. Kasami 수열 은 'Large set'과 'Small set'으로 분류되며 'Large set'은 모 든'Small set'을 포함한다. Large set'의 family size는 $2^{3 n / 2}+2^{n}$ 또는 $2^{3 n+2}+2^{n}-1$ 이며 'small set'의 family size 는 $2^{n / 2}$ 을 갖는다. 즉, Kasami 수열은 많은 family size를 가질 뿐만 아니라 'Large set'및'Small set'의 family size에 포함되어있는 수열들의 자기상관 및 상호상관 특성이 매우 우수하다 ${ }^{[9]}$. ATSC RP A/111에서 정의된 Kasami 수열은 생성다항식의 차수가 $n=16$ 인 'Large set'이며 생성다항식 $\mathrm{g}(x)$ 는 식 $(2)$ 와 같다.

$$
\mathrm{g}(x)=\mathrm{g}_{1}(x) \cdot \mathrm{g}_{2}(x) \cdot \mathrm{g}_{3}(x)
$$

where

$\mathrm{g}_{1}(x)=x^{16}+x^{12}+x^{3}+x+1$

$\mathrm{g}_{2}(x)=x^{16}+x^{12}+x^{11}+x^{9}+x^{8}+x^{4}+x^{3}+x^{2}+x+1$

$\mathrm{g}_{3}(x)=x^{8}+x^{7}+x^{6}+x^{3}+x^{2}+x+1$

여기에서 ' • '는 이진 곱셈을 나타내며 생성다항식 $\mathrm{g}(x)$ 에 상응하는 MSRG (modular shift register generator)
형태의 Kasami 수열 생성기는 그림 1과 같다.

그림 1의 Kasami 수열 생성기에 의하여 생성된 TxID 신 호는 BPSK (Binary Phase Shift Keying)변조된 이후 그림 2에서 보는 바와 같이 ATSC DTV 신호와 더해진다. TXID 신호는 ATSC DTV 신호와 더해지기 전 사전에 결정된 삽 입 레벨에 의하여 신호의 크기가 조절되며 여기에서 TxID 신호의 삽입 레벨은 기존의 ATSC DTV 시스템의 역호환 성을 고려하여 결정된다.

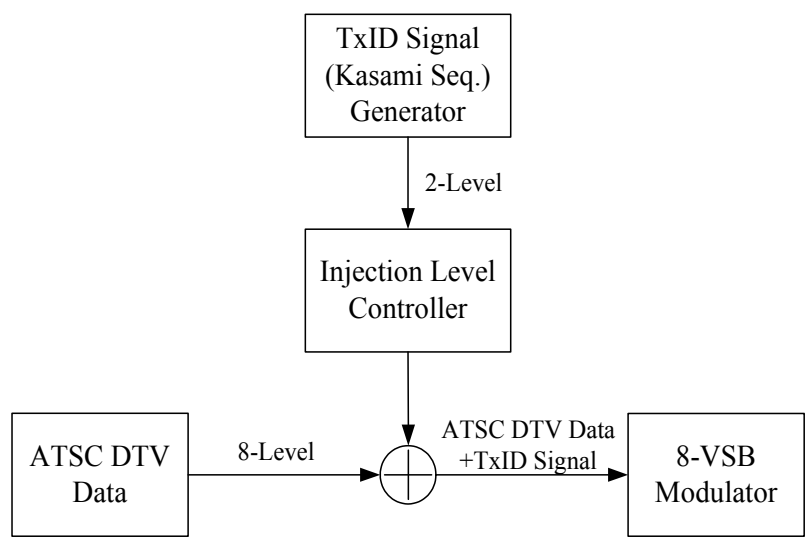

그림 2. TxID 신호의 삽입

Fig. 2. Insertion of TXID signal

삽입 레벨은 삽입된 Kasami 신호와 8-VSB 신호의 평균 전력비인 BR (Bury Ratio)을 이용하여 나타낼 수 있으며 $\mathrm{BR}$ 은 다음과 같다 ${ }^{[10]}$.

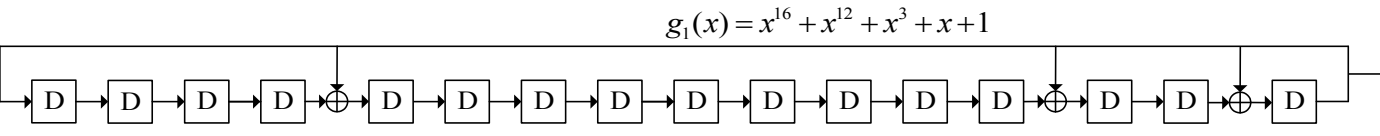

$g_{2}(x)=x^{16}+x^{12}+x^{11}+x^{9}+x^{8}+x^{4}+x^{3}+x^{2}+x+1$
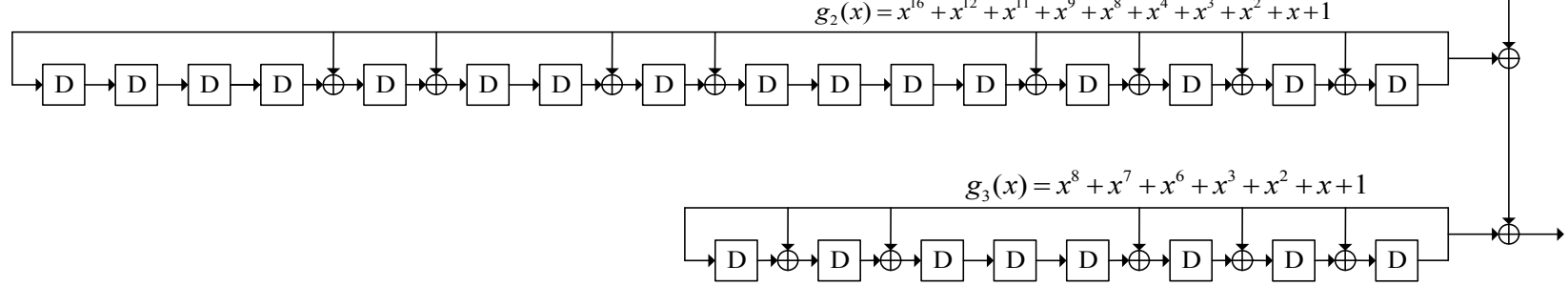

그림 1. Kasami 수열 생성기

Fig. 1. Kasami sequence generator 


$$
\mathrm{BR}=10 \log _{10}\left(\frac{\alpha^{2} E\left\{x^{2}(k)\right\}}{E\left\{d^{2}(k)\right\}}\right)
$$

여기에서 $d(x), x(k)$ 및 $\alpha$ 는 각각 시간 인덱스 $k$ 에서 의 ATSC DTV 데이터, BPSK 변조 된 Kasami 수열 및 삽 입레벨을 나타낸다. 8-VSB 방식을 사용할 경우 ATSC $\mathrm{DTV}$ 데이터의 심볼들은 8 레벨 $( \pm 1, \pm 3, \pm 5, \pm 7)$ 의 신호로 전송되므로 평균 파워는 $E\left\{d^{2}(k)\right\}=21$ 이고 BPSK 변조된 Kasami 수열의 평균 파워는 $E\left\{x^{2}(k)\right\}=1$ 이다. 따 라서 삽입 레벨 $\alpha$ 는 식 (4)와 같다.

$$
\alpha=\sqrt{\frac{21}{10^{-\mathrm{BR} / 10}}}
$$

ATSC DTV 시스템의 역호환성을 위하여 TxID 신호의 파워는 ATSC DTV 신호 파워보다 충분히 낮아야 하며 $\mathrm{ATSC} \mathrm{RP} \mathrm{A} / 111$ 에서는 8 단계의 $\mathrm{BR}$ 을 정의한다. 표 1 은 8단계의 BR에 따른 삽입 레벨 및 TOV (threshold of visi- bility)의 증가량을 나타낸다. AWGN 채널에서 전산실험을 통하여 ATSC DTV 시스템의 TOV 증가량을 확인한 것으 로 표 1에서 보는 바와 같이 TxID 신호의 삽입 레벨이 증가 함에 따라서 기존의 ATSC DTV 신호의 수신 성능이 열화 되는 것을 확인 할 수 있다 ${ }^{[11]}$.

표 1. BR에 따른 삽입레벨 및 TOV 증가량 [11]

Table 1. Injection level and TOV increments versus BR [11]

\begin{tabular}{|c|c|c|}
\hline Bury Ratio & Injection Level [Amplitude] & TOV 증가 [dB] \\
\hline$-21 \mathrm{~dB}$ & 0.40842248871983 & 1.0 \\
\hline$-24 \mathrm{~dB}$ & 0.28914097913688 & 0.5 \\
\hline$-27 \mathrm{~dB}$ & 0.20469613727266 & 0.2 \\
\hline$-30 \mathrm{~dB}$ & 0.14491376746189 & 0.1 \\
\hline$-33 \mathrm{~dB}$ & 0.10259109077387 & $<0.1$ \\
\hline$-36 \mathrm{~dB}$ & 0.07262893022873 & $<0.1$ \\
\hline$-39 \mathrm{~dB}$ & 0.05141734497976 & $<0.1$ \\
\hline
\end{tabular}

ATSC DTV 시스템의 프레임 구조는 그림 3과 같다. ATSC RP A/111에서는 ATSC DTV 신호에 워터마크 (watermark) 형태로 삽입되는 Kasami 수열은 필드 싱크

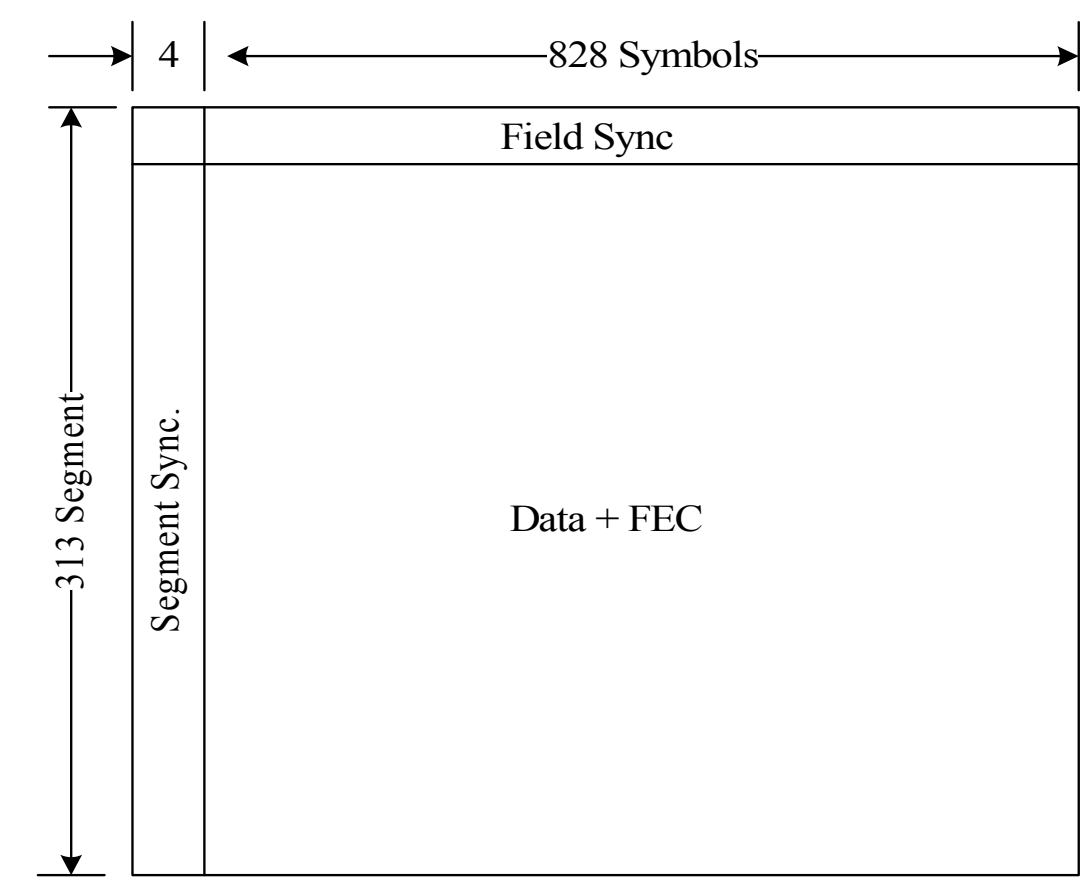

그림 3. ATSC DTV 시스템의 프레임 구조

Fig. 3. The frame structure of ATSC DTV system 
(Field Sync.)를 제외한 나머지 312개의 세그먼트 (segment)에 삽입되는 것을 권고하며 이 때 삽입되는 TxID 신 호의 총 심볼 (symbol)수는 259,584 심볼 (312 Seg. $\times 832$ Symbols/Seg.)이다. 주기가 65,535인 Kasami 수열을 VSB 데이터에 삽입하는 방법은 길이가 64,896인 4개의 truncated Kasami 수열 혹은 길이가 65,535인 3개의 Kasami 수 열과 길이가 62,979 인 1 개의 truncated Kasami 수열을 연접 하여 사용하는 방법이 있다다][6]. 본 논문에서는 길이 64,896 truncated Kasami 수열 4개를 연접하여 ATSC DTV 데이터 에 삽입하며 그 구조는 그림 4와 같다.

\section{The Proposed Scheme for additional data transmission}

ATSC DTV 신호와 TxID 신호의 프레임 구조는 그림 4
와 같다. 그림 4에서 보는 바와 같이 truncated Kasami 수열 의 주기는 64,896 이고 $\mathrm{VSB}$ 변조기의 심볼율이 10.76 $\mathrm{Msymbol} / \mathrm{s}$ 이므로 truncated Kasami 수열의 주기는 대략 $6 \mathrm{~ms}$ 이다. Kasami 수열의 위상과 극성을 이용하여 부가데 이터를 전송하면서 TxID 신호로서의 역할도 수행하기 위 해서는 Kasami 수열의 위상 변화가 최대 지연시간보다는 커야 TxID 신호 분석기를 통하여 채널 환경을 분석하는 것 이 가능하다. 따라서 SFN 방식으로 구성된 ATSC 지상파 $\mathrm{DTV}$ 시스템에서 신호의 최대 지연시간을 $\tau \mathrm{ns}$ 라고 가 정한다면 truncated Kasami 수열 하나의 주기에는 최대 6 $\mathrm{ms} / \tau \mathrm{ns}$ 개의 위상정보와 극성을 이용하여 부가데이터를 전송하는 것이 가능하다.

그림 5는 Kasami 수열의 극성과 위상을 이용하여 부가데 이터를 전송하기 위한 시스템 모델을 나타낸 것이다. 그림 5 에서 입력된 부가데이터는 직병렬 변환기 $(\mathrm{S} / \mathrm{P})$ 에 의하여

\begin{tabular}{|l|l|l|}
\hline $\begin{array}{c}\text { ATSC Field } \\
\text { Sync. }\end{array}$ & ATSC DTV Data \\
\hline
\end{tabular}

그림 4. 부가데이터 프레임의 구성

Fig. 4. Configuration of the additional data field

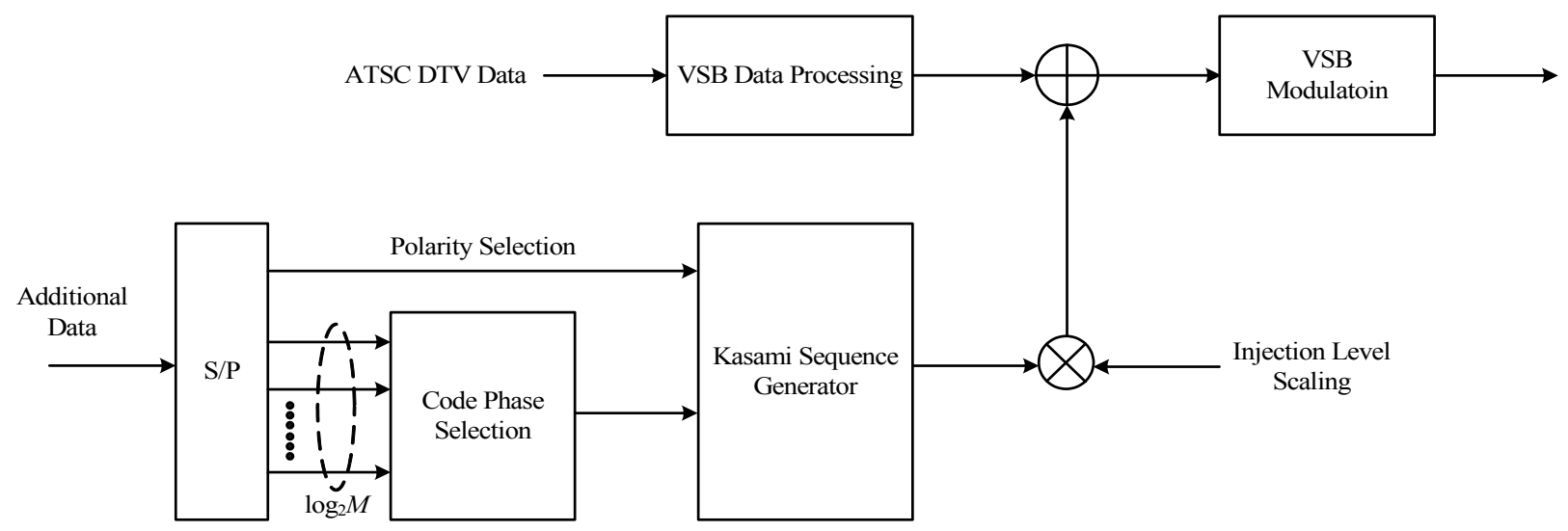

그림 5. 부가데이터 전송 송신기

Fig. 5. The additional data transmission transmitter 
$1+\log _{2} M$ 비트씩 묶여 병렬 비트로 출력된다. $1+\log _{2} M$ 비트의 직병렬 변환기 출력 중 첫 번째 비트는 Kasami 수열 의 극성을 결정하고 나머지 $\log _{2} M$ 비트는 총 $M$ 개의 위상 중 하나의 위상을 선택하기 위한 파라미터가 된다. 즉, $\log _{2} M$ 비트에 의하여 주기가 64,896인 truncated Kasami 수열은 $m \times 64,896 / M$ 만큼 위상이 변이 된다. 여기에서 $m=0,1,2, \ldots, M-1$ 의 값을 갖는다. Kasami 수열의 위 상 변화가 최대 지연시간보다는 커야 TxID 신호 분석기를 통하여 채널 환경을 분석하는 것이 가능하므로 위상 개수 $M$ 은 $\mathrm{SFN}$ 에서의 최대 지연시간을 고려하여 설정하여야 한 다. 본 논문에서는 국내에서 고려하고 있는 단일주파수 망 의 지연 분포 특성을 고려하여 최대 지연 시간을 대략 90 $\mu \mathrm{s}$ 로 설정하였으며 truncated Kasami 수열의 주기가 대략 $6 \mathrm{~ms}$ 인 것을 고려하면 $M=64$ ( $\simeq 6 \mathrm{~ms} / 90 \mu \mathrm{s}$ )까지 설정할 수 있다. $1+\log _{2} M$ 개의 비트에 의하여 Kasami 수열 위상과 극성이 결정된 이후에는 사전에 결정된 삽입 레벨에 의하여 신호의 크기가 조정 된 이후 VSB 변조 전 ATSC DTV 신호에 더해진다.

본 논문에서는 하나의 ATSC DTV 프레임 당 주기가 64,896인 truncated Kasami 수열 4개를 전송한다. 그림 4에 서 보는 바와 같이 $\operatorname{TxID} n, n=1,2,3,4$ 는 수열 위상과 극성 을 이용하여 각각 $1+\log _{2} M$ 개의 비트를 전송하므로 본 논문에서 제안하는 부가데이터 전송 기법은 하나의 ATSC DTV 프레임이 전송되는 동안 $4 \times\left(1+\log _{2} M\right)$ 비트의 부
가데이터를 전송한다. 따라서 하나의 ATSC DTV 프레임 의 길이가 약 $24.2 \mathrm{~ms}$ 이므로 이를 이용하여 부가데이터의 최대 전송율을 계산하면 식 (5)와 같다.

데이터 전송률 $=\frac{4 \times\left(1+\log _{2} 64\right) \mathrm{bit}}{24.2 \mathrm{~ms}}=1.157 \mathrm{kbps}$ (5)

그림 6은 부가데이터 전송을 위한 수신기 구조를 나타낸 것이다. 송신기 또는 중계기로부터 TxID 신호가 삽입된 방 송신호가 수신되면 튜너 (tuner)에서는 인접채널의 잡음을 제거하고 RF (Ratio frequency) 대역의 신호를 IF (intermediate frequency) 대역의 신호로 변환한다. IF 대역 의 신호는 동기화 (synchronization) 및 등화 (equalization) 과정을 거쳐 기저대역 신호로 변환된다. 안테나를 통하여 송신기 또는 중계기로부터 TxID 신호가 삽입된 방송신호 가 수신하고 기저대역 신호로 변환되는 과정까지는 기존의 ATSC DTV 시스템의 수신기와 동일한 구조를 갖는다. 기 저대역 신호는 각각 기존의 ATSC DTV 및 부가데이터 신 호를 처리하는 블록으로 전달된다. 부가데이터 신호를 처 리하는 블록으로 입력된 신호는 위상이 다른 $M$ 개의 Kasami 수열들과 상관을 취하고, 상관값의 크기가 최대가 되는 Kasami 수열의 위상과 극성 정보를 이용하여 Kasami 수열에 실려 전송된 부가데이터의 값을 추정한다.

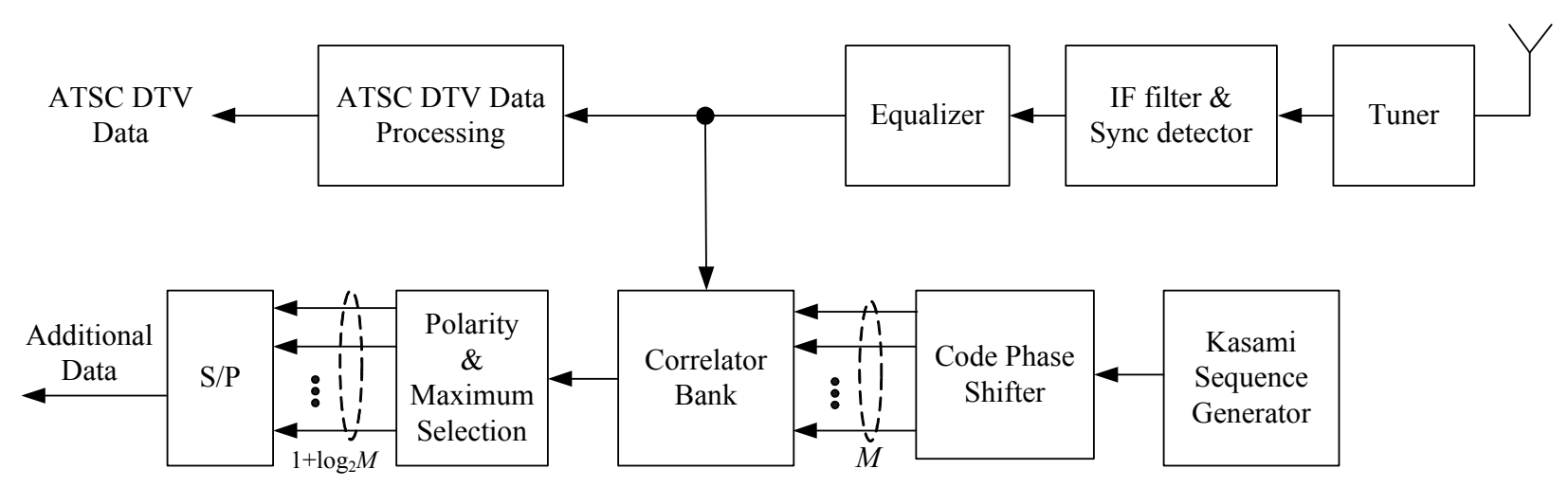

그림 6. 부가데이터 전송 수신기 구조

Fig. 6. The structure of receiver for additional data transmission 


\section{III. 전산 실험 결과}

본 논문에서는 Kasami 수열의 극성 및 위상을 조절하여 부가데이터를 전송하는 경우 Kasami 수열의 위상의 개수 에 따른 부가데이터 전송 기법의 비트오율 (bit error rate) 성능을 확인하기 위하여 전산실험을 수행하였다. 그림 7은 AWGN 채널에서 ATSC DTV 신호의 CNR에 대한 부가데 이터 전송 기법의 비트오율 성능을 나타낸 것이다. 여기에 서 TxID 신호와 ATSC DTV 신호의 전력비인 BR은 - 30 $\mathrm{dB}$ 로 설정하였다. $\mathrm{BR}$ 을 $-30 \mathrm{~dB}$ 로 설정할 경우 표 1 에서 보는 바와 같이 기존의 ATSC DTV 신호의 TOV는 $0.1 \mathrm{~dB}$ 증가한다 ${ }^{[11]}$. Kasami 수열의 위상 개수 $M$ 이 0 인 경우는 Kasami 수열의 극성만을 이용하여 부가데이터를 전송한다. 이는 논문 [7]에서 제안한 부가데이터 전송 기법과 동일이 며 이때 부가데이터의 전송율은 $165 \mathrm{bps}$ 를 갖는다. 위상 개 수 $M$ 이 8 인 경우는 Kasami 수열의 극성 뿐 아니라 위상을 조절하여 부가데이터를 전송한다. $M$ 이 8 인 경우는 $M$ 이 0 인 경우와 비교하였을 때 4 배 많은 부가데이터를 전송하 는 것이 가능하며 이때의 부가데이터 전송율은 $660 \mathrm{bps}$ 이 다. 기존의 DTV 신호의 주파수 및 시간 동기를 맞추기 위 하여 요구되는 최소한의 $\mathrm{CNR}$ 값은 $1.5 \mathrm{~dB}$ 이다 ${ }^{[7]}$. 따라서 동기를 맞추기 위하여 요구되는 최소한의 CNR 값과 부가 데이터의 비트오율 성능을 나타낸 그림 7의 결과를 통하여 $M$ 이 0 인 경우와 $M$ 이 8 인 경우 모두 부가데이터를 전송하

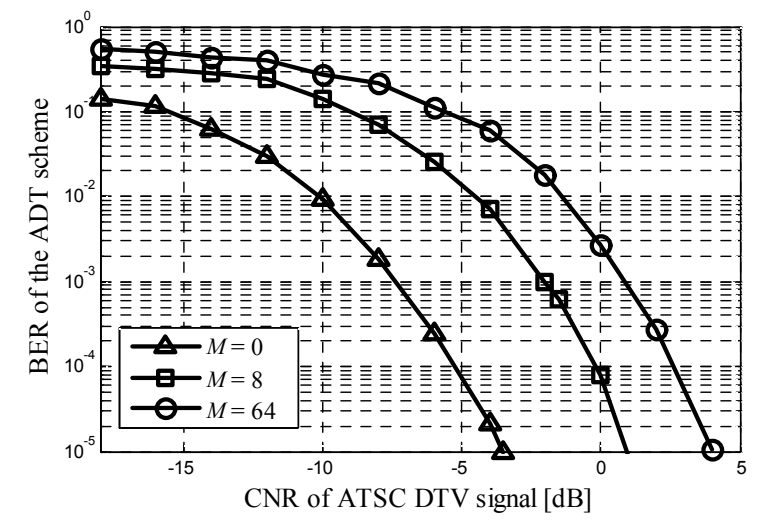

그림 7. 제안하는 부가데이터 전송 기법의 BER 성능

Fig. 7. BER performance of the proposed scheme
기 위하여 요구되는 최소한의 $\mathrm{CNR}$ 은 $1.5 \mathrm{~dB}$ 인 것을 알 수 있다.

위상 개수 $M$ 이 64 일 경우 부가데이터 전송 기법은 $1.157 \mathrm{kbps}$ 의 전송율로 부가데이터를 전송하는 것이 가능 하다. 그림 7에서 볼 수 있는 바와 같이 $M$ 이 64 일 경우 부가데이터 전송기법은 $\mathrm{ATSC}$ DTV신호의 $\mathrm{CNR}$ 이 $4 \mathrm{~dB}$ 인 영역에서 $10^{-5}$ 의 비트오율을 달성한다. ATSC DTV 시스 템에서 TOV를 만족하는 ATSC DTV 신호의 CNR이 15 $\mathrm{dB}$ 인 것을 고려하면 ${ }^{[2]}$ 방송이 정상적으로 동작하지 않는 영역에서도 제안하는 부가데이터 전송 기법이 정상적으로 동작한다. 따라서 부가데이터 전송 기법은 기존의 ATSC DTV 신호보다도 더 넓은 영역의 통신 반경을 갖는다.

\section{IV. 결 론}

본 논문에서는 $\mathrm{SFN}$ 방식으로 구성된 $\mathrm{ATSC}$ 지상파 DTV 시스템에서 송신기 및 중계기 송신 식별 신호로서 사용되는 TxID 신호를 이용하여 부가데이터를 전송하는 기법을 제안하였다. 또한, 제안하는 기법에서 사용하는 Kasami 수열이 ATSC RP A/111에서 제안하는 TxID 신호 로서의 기능을 수행할 뿐만 아니라 수열의 극성 및 위상을 이용하여 최대 $1.157 \mathrm{kbps}$ 의 데이터를 추가적으로 전송할 수 있다는 것을 확인하였다.

\section{참 고 문 헌}

[1] ATSC, "Standard A/110 : Synchronization Standard for Distributed Transmission," Advanced Television Systems Committee, Washington, D. C., July 2004.

[2] S. Kim, Y. Lee, S. Park, H. Eum, J. Seo, and H. Kim, "Equalization Digital On-Channel Repeater in Single Frequency Networks," IEEE Trans. on Broadcasting, vol. 52, no. 2, pp. 137-146, June 2006.

[3] Y. Lee, S. Park, H. Eum, J. Seo, H. Kim, S. Kim, and J. Seo, “A Design of Equalization Digital On-Channel Repeater for Single Frequency Network ATSC System," IEEE Trans. on Broadcasting, vol. 53, no. 1, pp. 23-37, Mar. 2007.

[4] K. Salehian, Y. Wu and B. Caron, "Design Procedures and Field Test of a Distributed-Translator Network, and a Case Study for an Application of Distributed-Transmission," IEEE Transactions on 
Broadcasting, vol. 52, no. 3, pp. 281-291, Sept. 2006.

[5] ATSC, "Recommended Practice A/111 : Design of Synchronized Multiple Transmitter Networks," Advanced Television Systems Committee, Washington, D.C., Sept. 2004.

[6] S. Park, J. Lee, H. Kim, and W. Oh, "Transmitter identification signal analyzer for single frequency network," IEEE Trans. on Broadcasting, vol. 54, no. 3, pp. 383-393, Sept. 2008.

[7] X. Wang, S. Park, H, Kim and Y, Wu, " Robust Emergency Communications Using TxID Watermark of ATSC DTV System", Journal of Communications, Vol. 4, No. 5, June 2009.

[8] S. Park, H. Kim, X. Wang, Y. Wu and W. Oh, "An efficient receiver structure for robust data transmission using TxID signal in the ATSC DTV system", in Proc. ICCE 2010, pp.17-18, Jan. 2010.

[9] D. V. Sarwate and M. B. Pursley, "Cross-correlation Properties of Pseudorandom and Related Sequences," IEEE Proc., Vol. 68, No. 5, pp. 593-619, May 1980.

[10] X. Wang, Y. Yu and B. Caron, "Transmitter Identification Using Embedded Pseudo Random sequence," IEEE Trans. Broadcasting, Vol. 50, No. 3, pp. 244-252, Sept. 2004.

[11] H. Mok, S. Park, J. Lee, J. Ryu and H. Kim, "The Analysis of TxID signal's Effect to Legacy Receivers in ATSC", Journal of Broadcast Engineering, Vol. 15, No. 3, pp. 414-425, May 2010.

[12] ATSC, "Standard A/54A : Guide to the Use the ATSC Digital Television Standard," Dec. 2003.

저 자 소 개

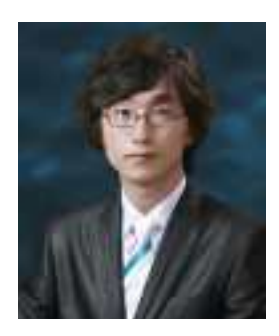

\section{강 동 훈}

- 2003년 3월 2009년 2월 : 충남대학교 전기전자정보통신공학부 (공학사)

- 2009년 3월 현재 : 충남대학교 정보통신공학과 석박사통합과정

- 주관심분야 : 오류정정부호, 디지털 통신

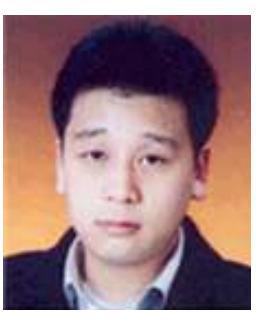

박 성 익

- 1996년 3월 2000년 2월 : 한양대학교 전자전기공학부 (공학사)

- 2000년 3월 2002년 2월 : 포항공과대학교 전자전기공학과 (공학석사)

- 2002년 2월 현재 : 한국전자통신연구원 방송시스템연구부 지상파방송기술연구팀 선임연구원

- 주관심분야 : 오류정정부호, 디지털 방송시스템, 디지털 신호처리

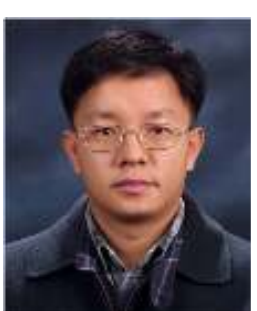

\section{김 흥 묵}

- 1989년 3월 1993년 2월 : 포항공과대학교 전자전기공학과 (공학사)

- 1993년 3월 1995년 2월 : 포항공과대학교 전자전기공학과 (공학석사)

- 1995년 3월 2001년 12월 : 포스코 기술연구소 연구원

- 2002년 1월 2003년 10월 : (주)맥스웨이브 연구개발팀 팀장

- 2004년 2월 현재 : 한국전자통신연구원 방송시스템연구부 지상파방송기술연구팀 팀장

- 주관심분야 : RF 신호처리, 디지털 신호처리, DTV 전송시스템 
저 자 소 개

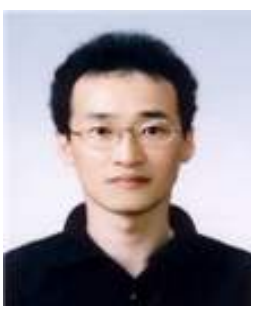

\section{오 왕 록}

- 1989년 3월 1994년 2월 : 포항공과대학교 전자전기공학과 (공학사)

- 1995년 3월 1997년 2월 : 포항공과대학교 전자전기공학과 (공학석사)

- 1997년 3월 2000년 2월 : 포항공대정보통신연구소 연구원

- 2000년 3월 2003년 8월 : 포항공과대학교 전자전기공학과 (공학박사)

- 2003년 8월 2006년 3월 : 포항공대정보통신연구소 연구원

- 2006년 4월 현재 : 충남대학교 정보통신공학과 교수

- 주관심분야 : 오류정정부호, 디지털 통신, DTV 전송시스템 